\title{
Data-Oriented Method to Big Data Standard System Creation: A Case of Chinese Financial Industry
}

\author{
Shuang Yang • Jianping Li · Jinjin Cai · Kun Guo • \\ Xinxin Gao • Fan Meng
}

Received: 10 October 2014 / Revised: 20 November 2014 / Accepted: 20 December 2014 /

Published online: 9 January 2015

(C) Springer-Verlag Berlin Heidelberg 2015

\begin{abstract}
Even though Big Data is a hot technology in the ICT industry with a large effect on economy and society, Big Data is a relatively indefinite concept, like a "laundry list",compared with cloud computing and Internet of things. Fortunately, there is a consensus that Big Data standardization can promote the exchange and scoping of data, guarantee the data completeness and timeliness, ensure the quality of further analysis, eliminate information islands and improve the industry efficiency. However, the existed methods to Big Data standard system are all technology-oriented. This paper proposes an integrated method, called data-oriented method, which combines bottom-up, top-down, method of expertise with investigation together, to build Big Data standard system based on the data essence in the special field. This approach makes the system get rid of pure technique thinking and adapt more to practical condition. Meanwhile, this research also gives a case study on Chinese financial industry in practice. According to that this data-oriented method sets a close and accurate links between special data and standard system, it can be applied on the construction of Big
\end{abstract}

S. Yang

College of Engineering and Information Technology, University of Chinese Academy of Sciences, Beijing 100049, China

J. Li (凶)

Institute of Policy and Management, Chinese Academy of Sciences, Beijing 100190, China

e-mail: ljp@casipm.ac.cn

J. Cai · X. Gao

Economic Information System Department, Communicating Technology Bureau, Xinhua News Agency, Beijing 100803, China

K. Guo · F. Meng

College of Management, University of Chinese Academy of Sciences, Beijing 100049, China 
Data standard system in other fields with improving the system model and laying a good foundation for Big Data applications and creations.

Keywords Big Data standard system - Data-oriented method · Chinese financial industy

\section{Introduction}

Big Data is a new concept in a specific stage of the development of information technology and Internet industry. From the Internet to the Internet of things, from cloud computing to Big Data, data requirements are from industrial base to the industry core [1]. The discussions about Big Data strategy, governance by data and open data are intense. Fortune said that Big Data has been favorably cast as "the new oil", to make value must carry on the processing and using the appropriate form of data [2]. According to the Big Data research results of the IDC [3,4] and McKinsey [5,6], Big Data can be mainly dug up a huge commercial value in the following four aspects: subdivision of customers, and then to the status of the each group of unique action; Big Data applications on simulate reality, explore the new demand and improve the rate of return on investment; improvement on Big Data results in sharing degree of each related department to improve the whole management chain and the industry chain investment returns; the innovation of business models, products and services.

Even though Big Data is a hot technology in the ICT industry with a large effect on economy and society, Big Data is a relatively indefinite concept, like a "laundry list",compared with cloud computing and Internet of things. That what technology, product, or service mode are suitable for Big Data is debated. Specially, unifying the professional and the unprofessional is not easy [7]. Otherwise, we need deeper excavation of relevance and a top-down thinking to take apart the financial data into blocks for more efficient analysis. Meanwhile, to eliminate data noise and to remove data redundancy in the process become increasingly important [8].

Obviously, institutions and individuals interface every day with many Present Shocks [9], they will be faster and deeper impact on production and our living environment. That it is good or bad depends on how it is used and its direction [10]. Big Data is not only shown on extension of technology and quantity, but also more important to be used in a wider range for more power savings to improve efficiency, to make the net bigger [11]. Everyone knows data is out there in large quantities, and it's not enough to simply know where it is - it has to be extracted, refined and delivered in a usable format to be valuable. Fortunately, there is a consensus that Big Data standardization can promote the exchange and scoping of data, guarantee the data completeness and timeliness, ensure the quality of further analysis and improve the industry efficiency [12]. Therefore, a comprehensive Big Data standard system is in great request, which also lays a great foundation for development and application of Big Data.

Big Data standard system is a collection of data standards in order to deal with problems faced with the integration operation and communication efficiency in the process of Big Data applications, involving the scope, content, type and formulated way of these standards. These standards can unify ideology and create a way to make a 
tedious process intelligible and acceptable. They can also promote the communications between different fields, which is very essential to Big Data. A lot of domestic and international standardization organizations are now working on the Big Data standard system construction. Many systems and creative methods are spawned.

Internationally, there are four standardization organization devoted to Big Data. ISO/IEC JTC1 SC32 established the group for the next generation of analysis technology and Big Data in 2012. Four new work projects for Big Data to provide standardization support were Launched in June, 2014. The key research objects of organization include metadata, data storage and retrieval, complex data types supported by Big Data, etc. In China, the National Information Technology Standard Communication (NIST) established the Big Data public working group (NBD-PWG) in 2013, whose key research objects include terms and definitions, cases and requirements, security and privacy, reference architecture and the technical route and so on. So far, there are some drafts in all these aspects.

Through the analysis to the existing standards of all the categories, discoveries are listed in the Table 1.

According to the existed systems, despite of the information in the table, for Big Data product and platform, there are some product management standards of database and un-structure data, lacking standards for visualization tools and data processing platform. In the environment of Big Data, data has become a kind of product. Standards for open data sets and data service platforms are indispensable but lacking [13]. Thus the existed methods to Big Data standard system are all technology-oriented. Therefore, a comprehensive enough method to construct a data standard system that satisfies the fast applications in a special field, is an urgent demand for research environment and the practical operations.

Standards in existing systems should further connect with the essence, characters and existing fields of data and meet more users' needs, and it is really an excellent way to ensure and verify the integrity of the system. That is to say that connections between standards and data styles, sources and structures are extremely important for being easily accepted popularly. Especially, in the Big Data era, complex data styles, various data sources and tremendous data structures are the distinguishing features. Otherwise, data assimilation [14] shows how different methods can be derived from a

Table 1 Big Data standardization condition in categories

\begin{tabular}{lll}
\hline Categories & Current situation & Future focus \\
\hline $\begin{array}{l}\text { Technical standards } \\
\text { Data sorting }\end{array}$ & A certain foundation & Improve and perfect \\
Data analysis & Some relevant standards & An urgent need to strengthen \\
Data access & Relatively lack & An urgent need to formulate \\
& $\begin{array}{l}\text { In development of standards on } \\
\text { databases, cloud data storage and } \\
\text { management class }\end{array}$ & $\begin{array}{c}\text { Lack of import or export data } \\
\text { standards }\end{array}$ \\
Data security & Some existing standards & Lack of standards on security \\
& framework, privacy, access control \\
Data quality & Standards in development, but not & Relatively lack \\
& yet released & \\
\hline
\end{tabular}


common theoretical basis, as well as how they differ or are related to each other, and which properties characterize them. Meanwhile, all these problems lead to that most of the commercial databases have self-built data standard systems, greatly weakening the credibility of general data standard systems.

Among the developments of standard systems, methods of global standardizersystems to form a standard system almost concentrate on bottom-up generalization (BUG) and method of expertise, like ISO or NITS, especially for guide makers $[15,16]$. Recently, someone tries to research another standardization way for better data application, and standardizer-systems have accepted other data application methods to standard systems for reaching a better result, like top-down method [17] and investigation [13] on the referable. No matter how methods are changing, a trend is obvious that data plays an increasingly important role on the process. The standardizer-systems have paid more attention on the trend and respect it generally. Simultaneously, this research proposes an integrated method, which integrates several methods together, to construct a data standard system solving the problems above and adapting more to Big Data, especially, on complex data styles, various data sources and tremendous data structures.

\section{An Integrated Approach to Big Data Standard System}

\subsection{Current Methods to Data Standard System}

In this research, the most essential creative highlights are concentrated on methods and correlativity between data and standards [18]. The creations ought to conquer the fields. Thereby, establish a different standard for data classification framework, which will be different from previous graphical tree structure, or may be a complicated network forms of organization. Not only can we adopt to knowledge of precipitation and lessons of essence that present financial data classification criteria creating experiences gain, but also analyze and mine existing data with more scientific instruments.

\subsubsection{Top-Down Specialization (TDS)}

Top-down specialization (TDS) [19] is a commonly used method for the construction of system, each skeleton carries an intermediate process. TDS considers the overall design and functional design from the highest level of the system structure in the initial stage of the Big Data standard system design. In the initial phase of the system design, that is the standard category stage. TDS determines main functions, key constraints, cooperate relationships and other important information. In the task allocation, these key constraints are assigned to each subsystem at the same time, and each subsystem should cooperate well and avoid conflict.

\subsubsection{Bottom-Up Generalization (BUG)}

Bottom-up generalization (BUG) is an effective way to write and formulate data standard, because each data standard has clear standardized plate. In the condition of 
the standardized objects known in advance, BUG is a pretty written way. Bottom-up tasks can be split to facilitate effective writing task as soon as possible [20]. Meanwhile, compared to the TDS, it is affected more by human factors, relying more on expert experiences and process inspections.

\subsubsection{Investigation}

Investigation is the most direct and fast means to understand the existing status. For standards and underlying data, there are needs to clarify the whole original content and context, determine the scope boundary and find out their inner link through investigation.

\subsubsection{Method of Expertise}

Method of expertise is an experience judgment method that depends on experts' experience and knowledge to offer evaluation and selection for technology development projects or schemes. For a way to establish the system in stages, method of expertise mentioned in this research is mainly reflected in expert personal judgment method and expert meeting method. Furthermore, it is recommended to introduce expert personal advice and open up expert discussion regularly in the process of system construction.

\subsection{Basic Data-Oriented Approach in Construction}

The creative approach is not only using basic methods before, but also integrated with a large number of investigation and reality analysis in data and data standard these two aspects for sorting and arrangement. Expert experiences and verifications make practical application and experience involved in the whole process of construction. This approach breaks through the normal thoughts that Big Data standard system is independent of data in a specific field and that the system could only meet the needs in the technology level. Corresponding standards to data from the beginning makes the standard system more acceptable and quicker apply on the practical use (Fig. 1).

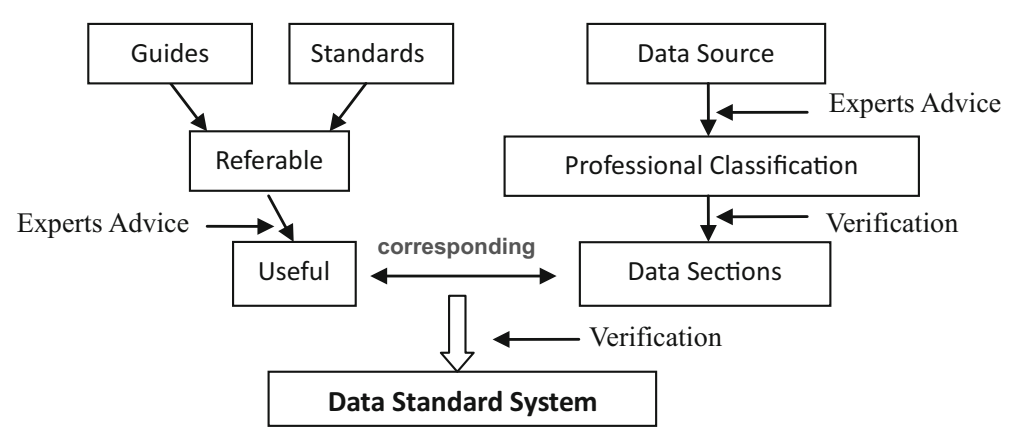

Fig. 1 Research approach 
Currently, the reasonable application of Big Data is the most accurate and sharpest way for search on objective facts. It is based on the internal essence of data, instead of throwing data into the continue change wave of technology. Data civilization development needs to be extended continuously. Rational use of Big Data is the only way to eliminate the data opinion gap between scientists and the public and information islands.

\subsection{Data-Oriented Method (DOM)}

Creating a complete network system, it is necessary to supported by a comprehensive method chain. This research adopts a creative method, which combines the TDS and BUG in the process of continued convergence and implementation with expert advice and investigation. On the whole of the Big Data standard system, the method provides the basis of the comprehensive methodology. The nature, type and scope of data that standards involve in are the key to construct standard system and the main basis of defining the scope of standards.

This kind of method design in the research makes flexibility good, which can satisfy the requirement of the system function design and reduce the repeated work due to add and modification. The design greatly improves the efficiency of the system. Moreover, with the development of the modern large-scale database and storage capacity, this kind of standard system based on data itself is easier to implement on the data platform. Flexible system design by interactive use of several methods is also convenient for standards' continuous improvement in the process of application (Fig. 2).

In the data-oriented method, creative points are various. Firstly, use an integrated method which combined with top-down method and bottom-up method with continuous verifications and injunctions of expert advice. Secondly, find a solution to combine the data sectors and relative data standards together. This solution must not interfere with the universality of the system, and it is convenient for the practicability of the system. Thirdly, find standards useful or wrote later according to not only technique needs, but also data categories. Therefore, the scope of research is expanded from a special field to all the relative data fields.

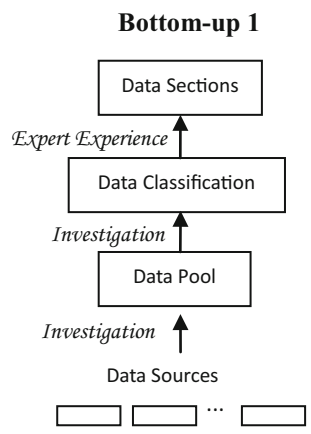

Bottom-up 2

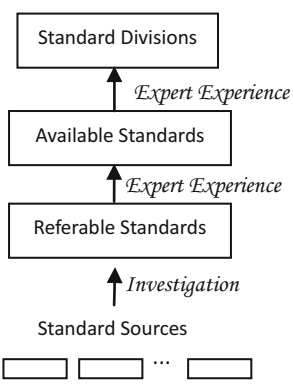

Top-down

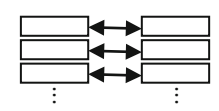

Standards for Data sections

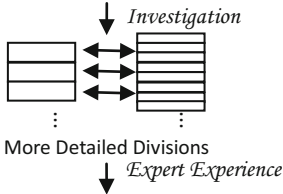

Big Data Standard System

Fig. 2 Data-oriented method 
For details, there are two sides which should be explained particularly. One side is about the practical use of expertise. The other side is that how to carry out investigation. They are critical links to rigorous foundations and qualification verifications for the whole DOM system.

Expertise is used in DOM for three purposes. Firstly, expert experience can help us ensure the integrity of data sources and contents. Secondly, the participation of experts make sure that standards and divisions can be representative and available. Thirdly, the construction of standard system should be practical and comprehensive, and expertise is the best and easiest way to give the verification.

Investigations which are carried out in DOM are always the first step of every part. An intelligent process should have a good foundation. Investigations provide the basic information and background for each process. They also give the original idea and theoretical basis to ensure the smooth verification later. Just like in the process of data collections, investigation helps us get the complete data sources and find the operational ways to obtain the data. Meanwhile, in the verification, the initial investigation paves the reference path to validate accuracy and supple missing data.

\section{A Case on Chinese Financial Industry}

\subsection{Characters of Big Data in Chinese Financial Industry}

Financial industry naturally has the data attribute. On the one hand, Big Data can provide adequate information support to the operation and management for financial institutions. On the other hand, new financial forms affected by Big Data brings serious challenges to traditional financial institutions. The international experience applied by Big Data in financial industry is mainly reflected on fast judgment on prediction of macroeconomic trends, analyzing customers and counterparties behavior, preventing fraud, improving internal efficiency, outsourcing noncore business and so on. Big Data's impacts on Chinese financial industry are mainly concentrated on building a comprehensive Big Data work and management system, enhancing the data mining and analysis skills, promoting smart financial market construction, forming the pricing system and promote risk management level.

In the era of Big Data, financial industry can break the information island, fully integrated with multi-channel customer transaction data and the operator personal financial information such as credit, consumption and behavior, to reduce risk. Big Data is a very frontier in the information revolution and a technique with the rapid development. Financial industry should work quickly to solve the internal data mining analysis and safety of the integrated utilization of external resources and to speed up the talent team construction and transformation of technical achievements. Through the effective application of Big Data, financial industry will accelerate transformation and upgrading as well as sustainable development.

In the era of Big Data, Chinese financial industry still has its own characteristics. The most significant is that data in the industry is highly centralized. Chinese finan- 
cial data is always divided into hot and cold data. Hot refers to higher frequency, bigger utilization rate and higher usage value. These data generally focus on transaction data, finance data and announcement data. Meanwhile, there are three aspects which are obviously reflected on Big Data. Firstly, data sources are increasingly multiple. Secondly, change of data types is faster. Thirdly, Big Data development in the banking is quicker than other sectors. Despite of these, in Chinese financial industry, the improvement is highly affected by economy policy and government guidance.

\subsection{Application Procedures}

Aimed at the characteristics of Big Data in Chinese financial industry, like multisource, multi-type and concentrated content, the financial data all need to be combed from the view of the source and the characters again, to form our own data classification system. Ensure that the Big Data Standard System built later in this field is of strong usability and wide enough coverage. Chinese data standards is docked with the international organizations' standards, then for further arrangements and classifications. These classifications accord with the current situation of China and can be for reference. Moreover, with adding some own additional categories, system will be more conducive to their own goals and later use and perfect. The four specific steps are as follows.

\subsubsection{Ensure the Sources, Contents and Classification of Data}

The main line is using BUG to form the data sections. Moreover, in this process, it is needed to investigate the main sources of financial and economic data sources in China, investigate and determine the main referable data classification method and integrate all of the data and constantly combine with the expert experience, so as to ensure rationality of classification and the integrity of data content and type.

\subsubsection{Get the Tables According to Application Purposes and Detailed Use}

The way is to make full use of BUG and method of expertise to form the data standards divisions, with the auxiliary of investigations. Research eventually will get referable financial Big Data standards list. According to the application purpose, there are tables for guides, international general financial data standards and national financial data standards respectively, and they all be further classified by detailed use. The guides in MFS standard system of IMF is shown in Table 2 that gives an example of investigation conclusion.

\subsubsection{Form the Preliminary Big Data Standard System Framework}

This procedure is the point of the whole application. The main line is fusing the TDS with method of expertise to form a framework. The list of Big Data standards available 
Table 2 Guides in MFS standard system of IMF

\begin{tabular}{llll}
\hline Name & Abbreviation & Field & Application \\
\hline $\begin{array}{l}\text { Monetary and finance statistics } \\
\begin{array}{l}\text { Financial soundness indicators: } \\
\text { compilation guide }\end{array}\end{array}$ & FFS & $\begin{array}{l}\text { Monetary and finance } \\
\text { Generalized finance }\end{array}$ & Data statistics \\
$\begin{array}{l}\text { Special data dissemination } \\
\text { General data dissemination }\end{array}$ & SDDS & Economy and finance & Data release \\
$\begin{array}{l}\text { Data quality assessment framework } \\
\begin{array}{l}\text { Data quality assessment framework } \\
\text { for monetary statistics }\end{array}\end{array}$ & DQAF & Economy and finance & Data release \\
\hline
\end{tabular}

is formed on the base of financial data classification, the referable standard, and Big Data application needs, combined with continuous expert experience. These available Big Data standards are filtered in accordance with the financial data classification. Moreover, standards for each sectors are further distinguished according to their own application purposes. Eventually, the preliminary Big Data standard system framework is formed.

\subsubsection{Gradually Improve the Big Data Standard System in Practice}

The improvement needs continuous verifications and practices. The standards in the table are released already or in the development. These standards need to be distinguish by adopted or modified. Adopted represents that it can be used directly, and modified represents that it should be revised and then adopted. After completing the sorting work, self-built standards are needed to be found in practice according to the demand, and new available standards should be focused on and adopted. Furthermore, observe and control in the process of system application constantly, and improve the Big Data standard system gradually.

\subsection{Framework of the System}

The final form in this research is the original version of the Big Data standard system framework based on the theories. In this framework, standards are classified in two levels: First one is the data related classification, and second one is the classification by function. Due to that the Big Data standard system is applied on Chinese financial industry, so this framework should firstly follow the completed China's financial sectors, corresponding relative standards to each sectors. Secondly, there are some ready-made standard categories which can be adopted for further classification. For Big Data standards, Chinese standardization institutions have divided the Big Data standards into specified categories according to their original purpose, like Table 1. Table 3 shows the preliminary and sketchy Big Data standard system framework in this research transferred and supplemented from a research earlier [21]. 
Table 3 Big Data standard system framework

\begin{tabular}{|c|c|c|c|}
\hline No. & Main category & Sub-categories & Corresponding references \\
\hline \multirow[t]{8}{*}{ A } & \multirow[t]{8}{*}{ Economy } & \multirow[t]{2}{*}{ A1 Global economy } & $\begin{array}{l}\text { BEC (Classification by Broad Economic Categories) } \\
\text { EGI (Handbook on Economic Globalisation Indicators) } \\
\text { BOPS (Balance of Payments Statistics) }\end{array}$ \\
\hline & & & Other General Standards and their Categories \\
\hline & & \multirow[t]{2}{*}{ A2 Macroeconomic } & SNA (System of National Accounts) \\
\hline & & & Other General Standards and their Categories \\
\hline & & \multirow[t]{2}{*}{ A3 Industries } & $\begin{array}{l}\text { ISIC (International Standard Industrial Classification of } \\
\text { all Economic Activities) } \\
\text { SNA2008, Chapter 4, Institutional Units and Sectors. }\end{array}$ \\
\hline & & & Other General Standards and their Categories \\
\hline & & \multirow[t]{2}{*}{ A4 Microeconomic } & IFRS (International Financial Reporting Standards) \\
\hline & & & Other General Standards and their Categories \\
\hline \multirow[t]{21}{*}{ B } & \multirow[t]{21}{*}{ Finance } & \multirow[t]{2}{*}{ B1 Currency } & $\begin{array}{l}\text { MFS (Monetary and Financial Statistics) } \\
\text { BIS Global Liquidity Indicators }\end{array}$ \\
\hline & & & Other General Standards and their Categories \\
\hline & & \multirow[t]{2}{*}{ B2 Banking } & $\begin{array}{l}\text { IBFS (Guidelines for reporting the BIS international } \\
\text { banking statistics) } \\
\text { MFS (Monetary and Financial Statistics }\end{array}$ \\
\hline & & & Other General Standards and their Categories \\
\hline & & \multirow[t]{2}{*}{ B3 Stock } & $\begin{array}{l}\text { MFS (Monetary and Financial Statistics) } \\
\text { Handbook on Securities Statistics, part } 3\end{array}$ \\
\hline & & & Other General Standards and their Categories \\
\hline & & \multirow[t]{2}{*}{ B4 Derivatives } & $\begin{array}{l}\text { MFS (Monetary and Financial Statistics) } \\
\text { BIS Derivatives Statistics }\end{array}$ \\
\hline & & & Other General Standards and their Categories \\
\hline & & \multirow[t]{2}{*}{ B5 Fixed income } & $\begin{array}{l}\text { MFS (Monetary and Financial Statistics) } \\
\text { Handbook on Securities Statistics, part } 2\end{array}$ \\
\hline & & & Other General Standards and their Categories \\
\hline & & \multirow[t]{2}{*}{ B6 Fund } & MFS (Monetary and Financial Statistics) \\
\hline & & & Other General Standards and their Categories \\
\hline & & \multirow[t]{4}{*}{ B7 Exchange } & $\begin{array}{l}\text { BPM6 (Balance of Payments and International } \\
\text { Investment Position Manual) }\end{array}$ \\
\hline & & & $\begin{array}{l}\text { BD4 (Benchmark Definition of Foreign Direct } \\
\text { Investment) } \\
\text { The new BIS effective exchange rate indices }\end{array}$ \\
\hline & & & $\begin{array}{l}\text { COFER (Currency Composition of Official Foreign } \\
\text { Exchange Reserves) }\end{array}$ \\
\hline & & & Other General Standards and their Categories \\
\hline & & B8 Isurance & General Standards and their Categories \\
\hline & & \multirow[t]{4}{*}{ B9 Others } & MFS (Monetary and Financial Statistics) \\
\hline & & & BIS Guides \\
\hline & & & OECD Guides \\
\hline & & & Other General Standards and their Categories \\
\hline $\mathrm{C}$ & Trading & C1 International trade & SITC (Standard of International Trade Classification) \\
\hline
\end{tabular}


Table 3 continued

\begin{tabular}{|c|c|c|c|}
\hline No. & Main category & Sub-categories & Corresponding references \\
\hline & & & BEC (Classification by Broad Economic Categories) \\
\hline & & & $\begin{array}{l}\text { MSITS2010 (Manual on Statistics of International Trade } \\
\text { in Services) }\end{array}$ \\
\hline & & & $\begin{array}{l}\text { SITS (Manual on Statistics of International Trade in Ser- } \\
\text { vices) }\end{array}$ \\
\hline & & & Other General Standards and their categories \\
\hline \multirow[t]{2}{*}{$\mathrm{D}$} & Government & D1 Government Finance & GFSM (Government Financial Statistics Manual) \\
\hline & & & Other General Standards and their categories \\
\hline \multirow[t]{2}{*}{$\mathrm{E}$} & Analysis & $\begin{array}{l}\text { E1 Volatility } \\
\text { E2 Trend }\end{array}$ & $\begin{array}{l}\text { Correspond to the appropriate analytical tools, including } \\
\text { the introduction of existing and own. }\end{array}$ \\
\hline & & E3 Icon & Other General Standards and their categories. \\
\hline $\mathrm{F}$ & News & $\begin{array}{l}\text { F1 Economic News } \\
\text { F2 Financial News }\end{array}$ & $\begin{array}{l}\text { Base on the classification of news agency itself, then to } \\
\text { do a little adjustment. }\end{array}$ \\
\hline
\end{tabular}

\section{Conclusion}

In the era of Big Data, the Big Data standard system promotes the exchange of data and improves the efficiency of industry. Meanwhile, it also makes Big Data maintenance risks and operational risks increase in applications [22]. Maintenance risks are loss of data, data leakage, data unauthorized tampering, decision making errors caused by asymmetric information in the process of data integration, etc. Operational risks include corporate reputation risk, management risk after the rivals access to data, etc. Therefore, the data control and data privacy protection must be strengthened. Furthermore, firstly, it is essential to attach great importance to the unified Big Data standards and promote the data cleaning and ensure the quality of data [23]. Secondly, define prudent border of data, and carry out the internal and external data sharing and non-core business outsourcing reasonably [24]. Thirdly, pay more attention to privacy protection and information security, and increase investment against network attacks.

Acknowledgments Thanks for the support from Xinhua Agency on the project-Standard General Principles for National Financial Information Platform. We shall extend our thanks to Mr. Ping Zhang (University of Michigan, Ann Arbor), Ms. Xini Wang (Harvard University), Ms. Shan Shan (Deloitte \& Touche), Ms. Xue Han (The Hartford.), Ms. Xinxin Pan (Carnegie Mellon University), etc. for all their valuable opinions and help in this research.

\section{References}

1. Mayer-Schonberger V, Cukier KN (2013) Big data: a revolution that will transform how we live, work, and think. Eamon Dolan/Houghton Mifflin Harcourt, New York

2. Clay Dillow. The big data employment boom [EB/OL]. http://fortune.com/2013/09/04/the-bigdata-employment-boom/

3. IDC (Dec 2013) Big data predictions 2014 Beyond irrational exuberance-opportunities in the big data and analytics markets [EB/OL]. http://www.idc.com/getdoc.jsp?containerId=WC20131211 
4. IDC. Big data and big data analytics: significance for the hardcopy industry [EB/OL]. http://www.idc. com/getdoc.jsp?containerId=246831

5. Biesdorf S, Court D, Willmott P (März 2013) Big data: what's your plan. McKinsey Quarterly

6. Manyika J, Chui M, Brown B, et al. (2011) Big data: the next frontier for innovation, competition, and productivity. McKinsey Global Institute

7. Tobias P, Helen S H, Eugene S (2013) Quantifying trading behaviour in financial markets using Google trends. Scientific Reports

8. Haag S, Cumming M (2012) Management information system for the information age, 9th edn. McGraw Hill HigheEducation, New York

9. Rushkoff D (2014) Present shock: when everything happens now. Current Trade

10. Robert J (2013) The new financial order: risks in the 21 st century. Princeton University Press, New York

11. Xu ZP (2014) Big data: history, reality and future[M]. China CITC Press, China

12. Hey T, Tansley S, Tolle K (2009) The fourth paradigm: data-intensive scientific discovery. Microsoft Res 26:88-95

13. National Information Technology Standard Communication (2014) The white paper of big data standardization. NITS Research

14. Evenson G (2009) Data assimilation: the ensemble Kalman filter, 2nd edn. Springer, Berlin

15. Anthony M (1989) F.UNEP/world bank expert meeting on environmental accounting and the SNA. Ecol Econ 1(3):283-285

16. Sédillot F, Pain N (2003) Indicator models of real GDP growth in selected OECD countries[R].OECD Economic Department Working Paper

17. Chiu C, Russell AD (2011) Design of a construction management data visualization environment: a top-down approach. Autom Constr 20(4):399-417

18. Zhang XY, Liu C, Nepal S et al (2014) A hybrid approach for scalable sub-tree anonymization over big data using MapReduce on cloud. J Comput Syst Sci 80(5):1008-1020

19. Bergadano F, Giordana A, Ponsero S (1989) Deduction top-down inductive learning[C]//Proceedings of the sixth international workshop on machine learning. Morgan Kaufmann Publishers Inc., Burlington, 23-25

20. Murat K, Gokhan E, Omer T (2014) Sustainability assessment of U.S. final consumption and investments: triple-bottom-line input-output analysis. J Clean Prod 81:234-243

21. Yang S, Guo K, Li JP et al (2014) Framework formation of financial data classification standard in the era of the big data. Procedia Comput Sci ICDS(2014) 30:88-96

22. Zvi B, Alex K, Alan JM (2011) Investments and portfolio management, 9 th edn. McGraw Hill Higher Education, New York

23. Wang DW, Liau CJ, Hsu TS (2007) An epistemic framework for privacy protection in database linking. Data Knowl Eng 61(1):176-205

24. Ohlhorst FJ (2012) Big data analytics: turning big data into big money. John Wiley \& Sons, New York

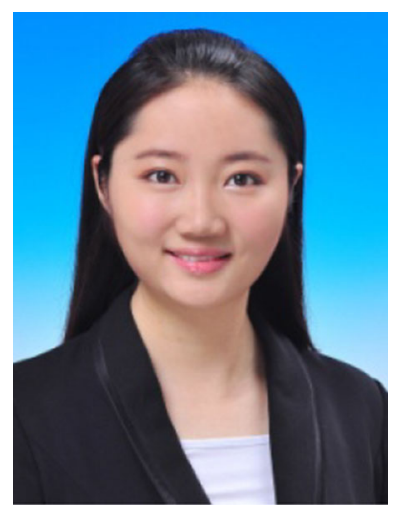

Shuang Yang was born in Anhui, China in 1991. She graduated at Renmin University of China, School of Statistics in 2012. She is currently a master student in University of Chinese Academy of Sciences and a research assistant in Institute of Policy and Management, Chinese Academy of Sciences. Her research interests include financial big data, data standardization and optimization based data mining. 

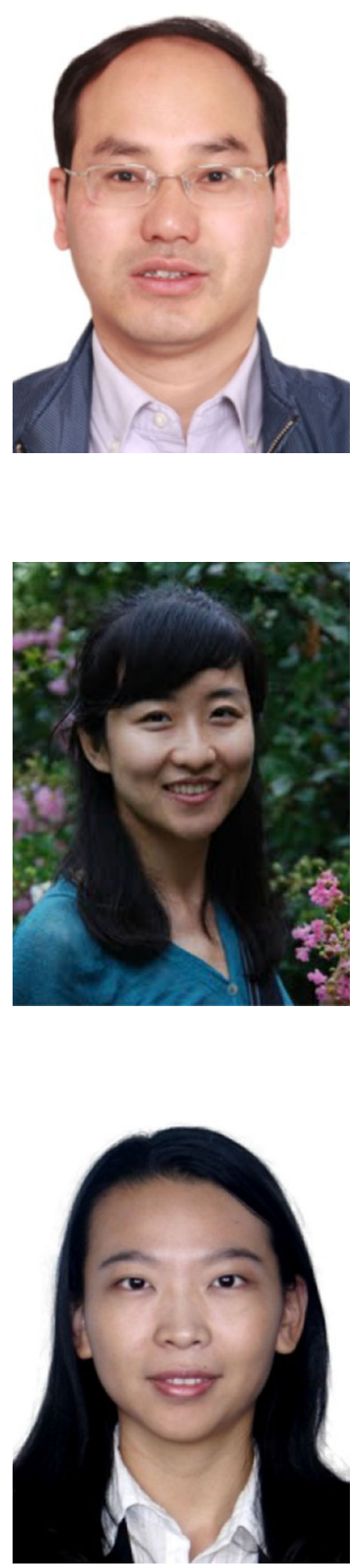

Jianping Li received the Ph.D. degree in Management Sciences and Engineering from University of Science and Technology of China, Hefei in 2004, and currently is a professor in Institute of Policy and Management, Chinese Academy of Sciences. Prof. Li is the secretary and executive committee member of International Academy of Information Technology and Quantitative Management (IAITDM). He has published 4 monographs and over 100 papers in various journals and conferences/proceedings. His research interests include bank risk modeling, optimization based data mining.

Jinjin Cai received her Computer Software and Theoretic Master degree in Institute of Computing Technology, Chinese Academy of Sciences. Currently she is working in Economic Information System Department, Communicating Technology Bureau, Xinhua News Agency. Her research interests include the new media, financial IT System Architecture and Development.

Kun Guo was born in Shandong, China in 1983. She graduated Management Science and Computer Science and Technology specialization at Beijing Normal University, School of Management and School of Information in 2006. And she obtained her doctoral degree in Management Science and Engineering in 2011 from University of Chinese Academy of Sciences. Currently she is assistant professor at Research Center on Fictitious Economy and Data Science, Chinese Academy of Sciences. Her research interests include fictitious economy and complex system. 


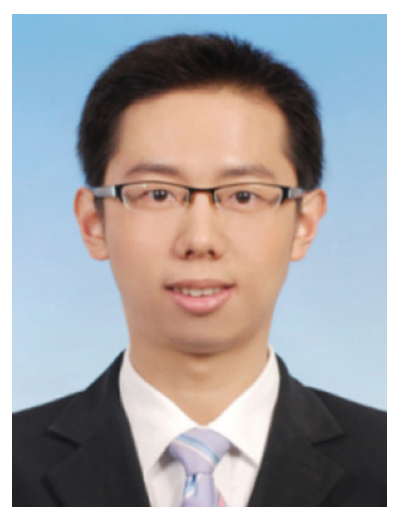

Xinxin Gao received his master degree in Information and Signal Processing from Beijing University of Posts and Telecommunications. Currently he is working in Economic Information System Department, Communicating Technology Bureau, Xinhua News Agency. His research interests include the new media, data of news and big data.

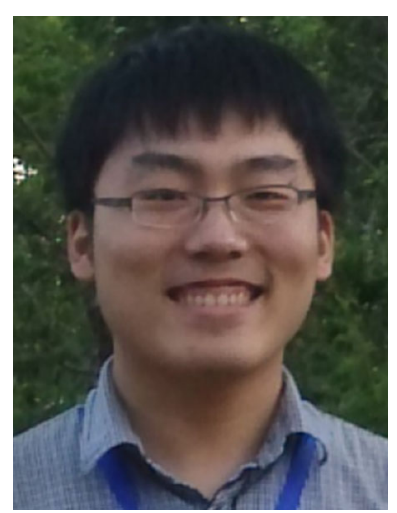

Fan Meng was born in Henan, China in 1989. He graduated Information Management and Information System specializations at Peking University in 2012. He is currently a PhD student and teaching assistant in University of Chinese Academy of Sciences. His research interests include edge detection, image segmentation and optimization based data mining. 